EESTI NSV TEADUSTE AKADEEMIA TOIMETISED. XVII KÖIDE

KEEMIA * GEOLOOGIA. 1968, Nr. 1

ИЗВЕСТИЯ АКАДЕМИИ НАУК ЭСТОНСКОЙ ССР. ТОМ ХVII

ХимИЯ * ГЕОЛОГИя. 1968, № ।

\author{
B. ВАХЕССАAР, И. КЛЕСМЕНТ, О. ЭНЗЕН
}

\title{
ОПРЕДЕЛЕНИЕ ГРУППОВОГО СОСТАВА ФЕНОЛОВ ПРИ ПОМОЩИ ТОНКОСЛОИНОЙ ХРОМАТОГРАФИИ
}

Фенолы, выделяемые из сланцевых смол, представляют собой сложную смесь. Они содержат множество соединений, имеющих скелет ароматического углеводорода разной структуры. Кислород входит в состав гидрокснльной и других функциональных групп. Группы фенолов различаются свойствами и реакционной способностью, поэтому использование такой сложной смеси практически затруднено. При использовании сланцевых фенолов авторы попыталнсь разделить их на две основные группы по количеству гидроксильных групп: одноатомные и двухатомные фенолы. Фенолы разделились между этими двумя группами по кислотностям (метод парциальной дефеноляции) [3] или по разностям растворимости в полярных растворителях [4].

При использовании фенолов следует знать содержание этих двух основных групп в исходном веществе. Самым простым методом определения его является расчет по среднему молекулярному весу смеси и содержанию гидроксильных групп $\left[{ }^{1},{ }^{2}, 5\right]$. Метод является неточным, так как группы в болышинстве случаев распределены в исходном веществе́ неравномерно, их отношения измєняются вместе с температурой кипения. В последнне годы для определения группового состава фенолов использовался и метод распределительной хроматографии $[6,10]$. Разделяются $10-20$ г вещества, при этом адсорбентом используется силикагель, сольвентами - этиловый или метиловый спирт и бензол. Недостатком этого метода явллется его продолжительность.

Хроматографирование можно провести бьстрее и с большей селективностью, используя тонкослойный метод. Последний применяется в основном для идентифицирования органических веществ - для качественного анализа. Препаративная часть этого метода успешно применялась и при определении группового состава масел $\left[{ }^{15}\right]$, и как вспомогательный метод при газохроматографическом анализе фенолов [11, $\left.{ }^{14}\right]$. В последней работе [14] выяснилось, как фенолы разделяются в тонком слое на группы, з зависимости от их полярностей. Следовательно, является возможным и определение группового состава фенолов. Тонкослойная хроматография по сравнению с другими методами имеет ряд преимуществ: непродолжительность хроматографирования $(0,5-1$ ч), что позволяет анализировать и малостабильные вещества, минимальный расход материалов, высокая четкость разделения, которая обусловливается относительно большим количеством, адсорбента (весовое отношение разделяемого вещества и адсорбента $1: 160$, тогда как при хроматографировании в колонке это отношение $1: 25)$.

Целью данной работы было выяснение оптимальных условий для разделений в тонком слое, практическое исследование влияния разных адсорбентов и растворителей, а также селективности разделения на группы для узко- и высококипящих фракций фенолов. 


\section{Методика работы}

В соответствии с методикой разделения соединений для анализа использовались стеклянные пластинки разных размеров. Пласгинки размерами $120 \times 180$ мм (толщина слоя адсорбента 0,25 мм) и $200 \times 200$ мм (толщина слоя 0,5 мм) использовались для определения относительных растояний выхода различных индивидуальных фенолов, чтобы выяснить оптимальные условия разделения.

В качестве адсорбента использовались слои окиси алюминия и закрепленные и незакрепленные слои силикагеля, в качестве элюента смесн относительно полярных растворителей, например дихлорэтан и этилацетат в отношениях $3: 1,6: 1$ и $9: 1$, бензол и этиловый спирт $9: 1$ и чистые растворители - дихлорэтан и др. Детектировали парами йода и УФ-лучами.

Практически в анализируемых смесях можно встретить разные типы фенолов, а также и нейтральные соединения. С целью исследования условий разделения, для многих индивидуальных веществ были определены относительные расстояния выхода. Среди использованных фенолов были одно- и двухатомные фенолы с разными алкильными цепями, фенолы с нейтральным кислородом и нейтральные кислородные соединения.

$R_{f}$ зависит от полярностей соединений, следовательно, и от количества гидроксильных и других полярных грушп, а также от их взаимного расположения. Известно [12], что двухатомные фенолы адсорбируются сильнее, чем одноатомные, и остаются в начале пластинки. Ортоалкилфенолы адсорбируются слабее, в зависимости от так наз. ортоэффекта - ослабления влияния полярной гидроксильной группы, так как ее экранирует близко расположенная алкильная группа. Ортоэффект полезен при исследовании фенолов, принадлежащих к одной и той же группе. В других случаях ослабленная ортоэффектом адсорбция обусловливает движение двухатомных ортоалкилфенолов к одноатомным фенолам.

Значит, мы должны найти такие условия разделения, при которых влияние ортоэффекта было бы незначительным, а разделение групп четким.

В табл. 1 приведены относительные расстояния выхода в тонком слое различных эталонов.

Вообще силикагель является более сильным адсорбентом, чем окись алюминия. Ясно и то, что для передвижения фенолов на окиси алюминия нужен более полярный сольвент, так как в зависимости от щелочных свойств окиси алюминия фенолы на нем адсорбируются сильнее. При слое силикагеля можно применять и менее полярные растворители, например чистый дихлорэтан, При однократном элюировании дихлорэтаном значительного передвижения фенолов не наблюдается. Передвижение фенолов к середине пластинки и их более селективное разделение между собой достигается при не менее чем двухкратном элюировании с просушиванием пластинки после каждого элюирования.

Результаты анализа показывают, что в силу щелочных свойств окиси алюминия фенолы удерживаются на нем сильнее, чем на силикагеле. Поэтому правомерно предположение, что в случае еще более щелочного адсорбента удерживание увеличивается и фенолы в зависимости от их кислотности разделяются больше. С этой целью к окиси алюминия была добавлена гидроокись натрия. Прибавление 1\% $\mathrm{NaOH}$ никакого влияния не оказало. Добавление $3 \% \mathrm{NaOH}$ оказало некоторое влияние: 
$R_{f}$ индивидуальных соединений в тонком слое

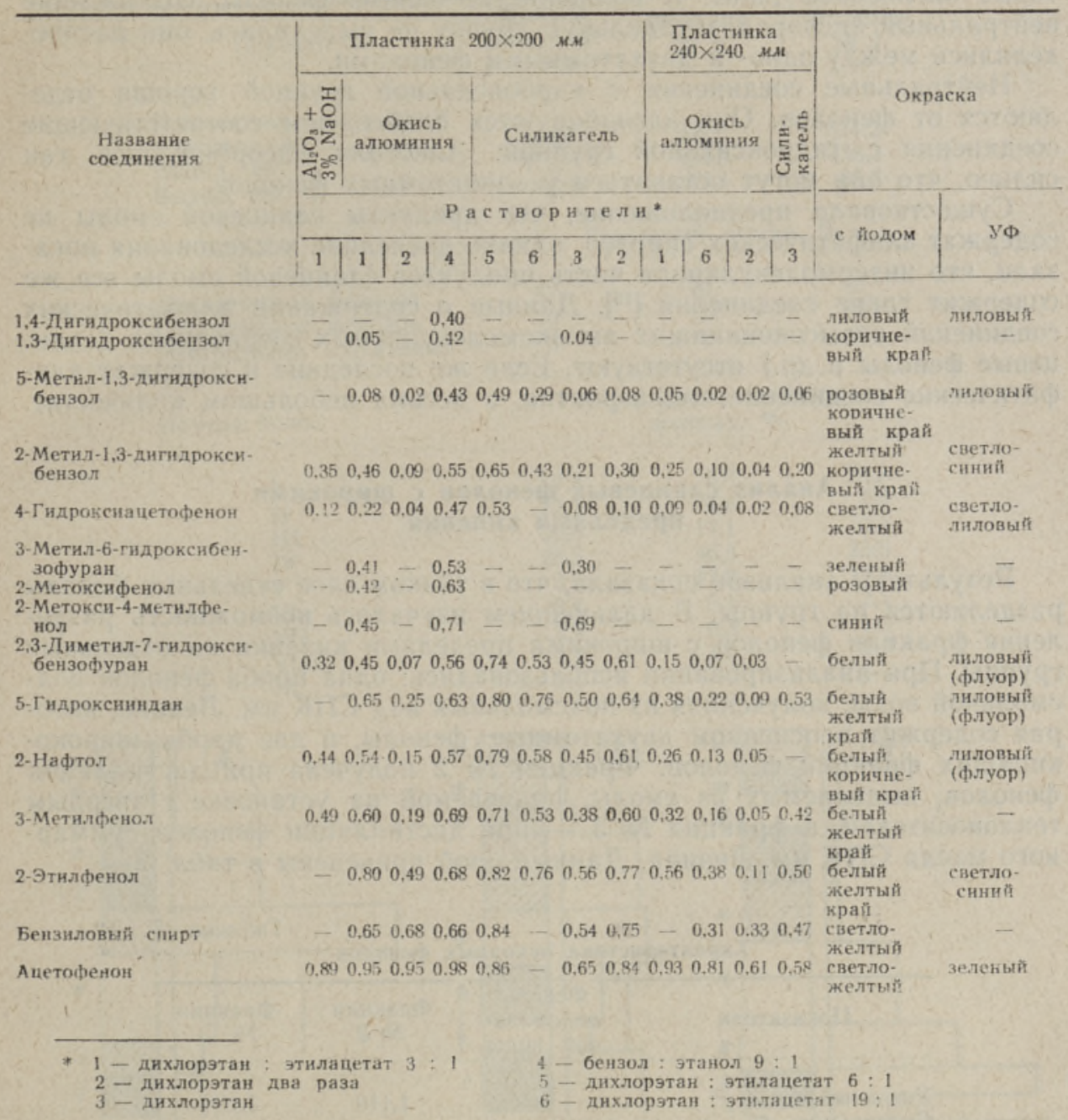

фенолы удерживались больше, но селективность группового разделения не изменялась. Таким образом, добавление гидроокиси натрия желательного эффекта не дает.

Из результатов проведенных опытов следует, что на окиси алюминия при использовании смеси растворителей дихлорэтана и этилацетата внутригрупповое разделение происходит лучше, чем на силикагеле, однако ухудшается межгрупповое разделение (например, 2-метил-1,3-дигидроксибензол слишком приближается к одноатомным фенолам) Несколько лучше разделение одно- и двухатомных фенолов на силикагеле.

При использовании смеси растворителей бечзола и этилового спирта внутригрупповое разделение хуже и межгрупповое разделение не очень четкое.

Отдельной проблемой являются фенолы, содержащие нейтральный кислород. Из них были использованы только фенолы, содержащие карбонильную группу в положении 4 по отношению к гидроксильной группе 
(функциональная группа с нейтральным кислородом изолирована от гидроксильной группы), из алкоксифенолов - 2-алкоксифенолы и некоторые оксибензофураны. В большинстве опытов фенолы, содержащие нейтральный кислород, в отдельную группу не выделились, они распределились между одно- и двухатомными фенолами.

Нейтральные соединения с карбоксильной группой хорошо отделяются от фенолов. Они адсорбируются слабее, чем соответствующие соединения с гидроксильной группой. Алкоголи адсорбируются так сильно, что они могут оставаться у одноатомных фенолов.

Существовало предположение, что продукты сланцевой смолы не содержат алифатических спиртов, однако последние исследования показали, что низкомолекулярная часть продуктов сланцевой смолы все же

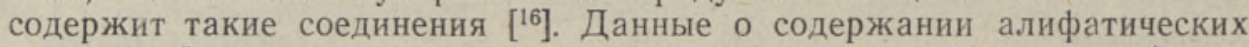
соединекий в высококипящих высокомолекулярных соединениях (сланцевые фенолы и др.) отсутствуют. Если же последние и содержат алифатические соединения, то, вероятно, в весьма небольшом количестве.

\section{Анализ сланцевых фенолов с широкими пределами кипения}

Результаты анализов показали, что в тонком слое отдельные фенолы разделяются на группы. В дальнейшем изучалась возможность разделения фракции фенолов с широкими пределами кипения на отдельные группы. При анализировании использовались: одна проба фенолов подсмольной воды, полученная из подсмольных вод СПК им. Ленина, которая содержит в основном двухатомные фенолы, и две пробы ширококипящих фракций фенолов. Фракция № 2 получена при дистилляции фенолов, выделяемых из смолы, получаемой на установке с твердым теплоносителем, а фракция № 3 - при дистилляции фенолов суммарного масла СПК им. Ленина. Данные проб приведены в табл. 2.

Таблица 2

Характеристика исходных фенолов

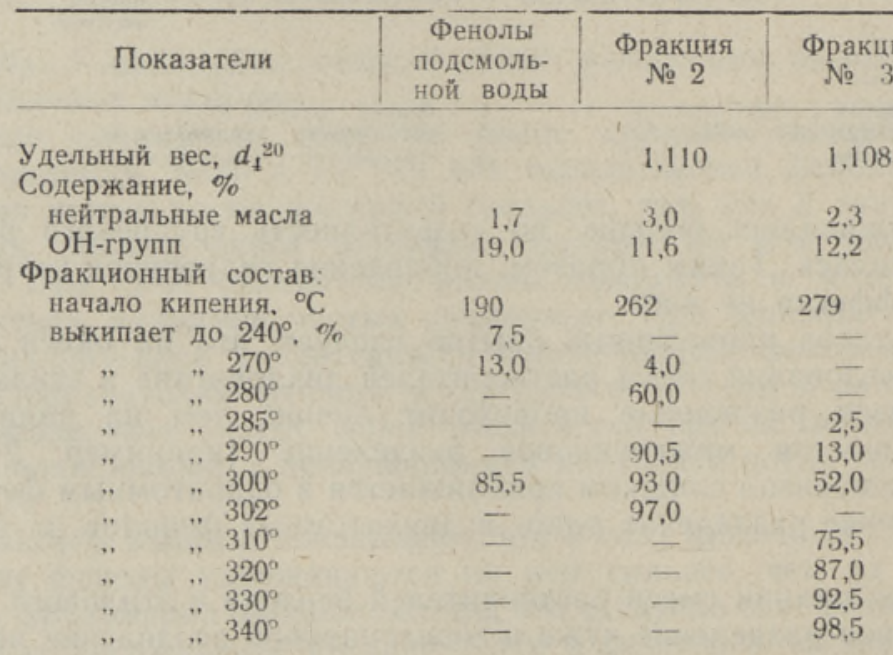

Для препаративно-количественного анализа пластинки размером $240 \times 240$ м.м при толщине силикагеля $(0,08-0,125$ мм) 2,0 мм [17].

были использованы закрепленного слоя 


\section{таблица 3}

Материальный баланс разделения фракции фенолов в закрепленном тонком слое силикагеля

\begin{tabular}{l|c|c|c}
\hline \multicolumn{1}{c}{ Показатели } & $\begin{array}{c}\text { Фенолы } \\
\text { подсмоль- } \\
\text { ной воды }\end{array}$ & $\begin{array}{c}\text { Фракция } \\
\text { № 2 }\end{array}$ & $\begin{array}{c}\text { Фракция } \\
\text { № } 3\end{array}$ \\
\hline Количество исходного & & & \\
$\begin{array}{l}\text { фенола, не } \\
\text { Выхсд, мг }\end{array}$ & 500,4 & 508,6 & 511,2 \\
Выход, вес. \% & 470,1 & 494,9 & 438,1 \\
& 94,0 & 97,3 & 85,7 \\
\hline
\end{tabular}

Групповой состав, \%

$\begin{array}{lrrr}\text { Двухатомных фенолов } & 87 & 29 & 43 \\ \text { Одноатомных фенолов } & 10 & 69 & 55 \\ \text { Нейтральных соединений } & 3 & 2 & 2\end{array}$

Номера полос

I
II
III
IV
V
VI
VII
VIII
IX
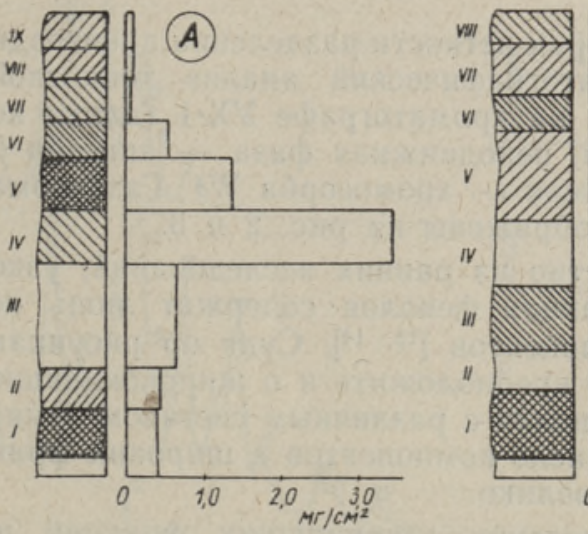

Распределение вещества в

$\frac{13}{3}$
2
2

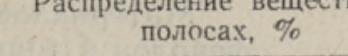


соединения. Границу между этими группами легко найти, если нанести на оба края пластинки эталоны, например 2-метил-1,3-дигидроксибензол, 2-нафтол и какой-нибудь 2-алкилфенол.

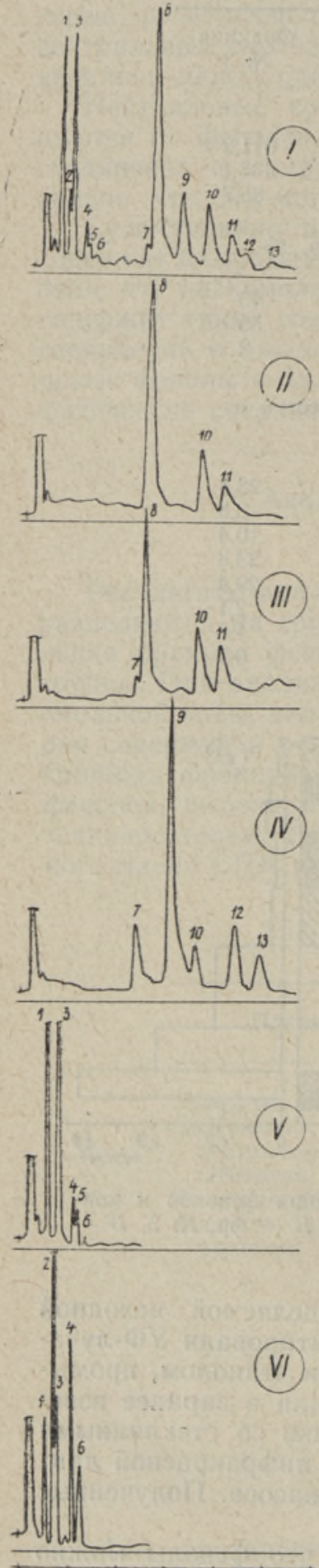

В настоящей работе нас интересовало и внутригрупповое разделение - либо по расположению отдельных компонентов, либо по концентрации вещества на пластинке. Количество собранных полос - 8-9. При осмотре в ультрафиолетовом свете полосы разделяли и по окраске. В некоторых случаях полосы проявляли и парами йода, так как кратковременное проявление йодом не оказывает заметного влияния на материальный баланс и состав фенолов. В начале хроматограммы количество полос было столь велико, что выделить все раздельно было практически невозможно.

Материальный баланс и разделение фракции фенолов в тонком слое приведены в табл. 3 . На рис. 1 изображены концентрации веществ в тонком слое.

Фенолы подсмольной воды содержат преимущественно двухатомные фенолы, которые адсорбируются значительно сильнее всех остальных. У фенолов сланцевой смолы наблюдается разделение на две группы. В высококипящих фракциях содержание двухатомных фенолов гораздо выше.

Для проверки четкости разделения производили газохроматографический анализ тонкослойных фракций на хроматографе УХ-1 (длина колонки - $6 \mu$, неподвижная фаза - апиезон L, $15 \%$ от носителя - хромосорба W). Газохроматограммы изображены на рис, 2 и 3.

Как известно из ранних исследований, узкокипящие фракции фенолов содержат лишь несколько компонентов $\left[{ }^{13},{ }^{14}\right]$. Судя по рисункам, то же можно предположить и о ширококипящих фракциях фенолов с различным составом. Выяснилось, что число компонентов в широких фракциях не так велико.

При разделении узкокипящих фракций на неполярной апиезоновой колонке раньше всех отдельной группой выходят двухатомные фенолы. Давление паров отдельных компонентов ширококипящих фракций различно, что влияет и на расстояние выхода компонентов в газохроматографе. Поэтому на газохроматограммах однои двухатомные фенолы смешаны.

Рнс. 2. Газохроматограммы тонкослойных фракцнй фенолов подсмольной воды.

Условия хроматографирования: длина колонки -6 ж; наполннтель - апнезон L, $15 \%$ от хромосорба W; температура $197^{\circ} \mathrm{C}$; расход водорода - 120 жл/мин; давление - 2,4 атм. 
Очень легко определить содержание одно- и двухатомных фенолов в фенолах подсмодьной воды. Поскольку число индивидуальных фенолов в них не велико, оказалось возможным идентифицировать отдельные компоненты. Они содержат очень много 5-метил- и 2-метил-1,3-дигпдроксибензолов, которые в тонком слое полностью отделились друг от друга. Одноатомные фенолы разделились на две группы: фенолы с экранированной и неэкранированной гидроксильной группой. Из одноатомных видны фенол, 2-метил-, 3-метил- и 4-метилфенолы. Содержание фенолов с большим временем выхода незначительно.

Данные о фенолах подсмольных вод СПК им. Ленина были уже раньше представлены в работах ряда авторов $[7,8,9]$.

\section{Содержание двухатомных фенолов в фракциях смолы туннельных печей}

Мы использовали узкокипящие фракции фенолов, выделенные из пропорциональной смеси бензина и легкой смолы туннельных печей. Ранее исследовался состав фракции фенолов, кипящих в пределах $192-290^{\circ} \mathrm{C}$ $\left[{ }^{13},{ }^{14}\right]$. В данной работе определено содержание двухатомных фенолов

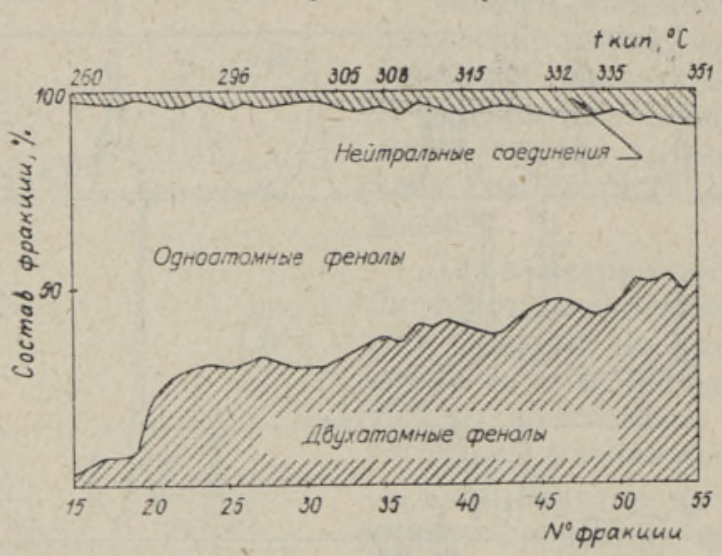

Рис. 4. Групповой состав фенолов, выделенных из легкой смолы туннельных печей.

на, кипящих именно в этих пределах.

Данных о групповом составе высококипящих фенолов в литературе

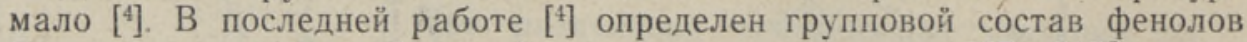
бензино-керосиновых фракций, кипящих в пределах 265-315\%: одноатомных фенолов - 33\%, двухатомных - 44,5\%, гетероциклических фенолов и моноэфиров двухатомных фенолов - 22,5\%. Полученные нами данные о содержании двухатомных фенолов близки к вышеуказанным. Значение полученных результатов уменьшается тем, что нейтральные кислородсодержащие фенолы нельзя было выделить в отдельную группу и они распределились между одно- и двухатомными фенолами.

Таким образом установлено, что окись алюминия и силикагель как

Рис. 6. Газохроматограммы тонкослойных фракций фенолов туннельных печей фракции № 31 Адсорбент: $A-$ силикагель, $B$ - окись алюминия.

Условня хроматографи, вания: хроматограф єПайь; длина колонки - 1,2 $\boldsymbol{м}$; неподвижная фаза апнезон L. $15 \%$ от носн.еля хромосорба W: температура $-200^{\circ} \mathrm{C}$; расход аргона: $A-50$ мл/мин; Б -44 мл/мин; давленне: $A-0,42$ ат., $B-0.38$ атм. 
адсорбенты имеют различные свойства. Для выяснения способности разделения обоих адсорбентов производили сравнительные анализы фракции туннельных смол № 31 с пределами кипения $303-305^{\circ}$. Препаративные тонкослойные хроматограммы фенолов фракции № 31 изображены на рис. 5. Газохроматографическая хаРис. 5. Препаративные тонкослойные хроматогрзммы фенолов и концентрации разделенных фенолов в полосах фракцин № 31:

$A$ - на силикагеле, $B$ - на окиси



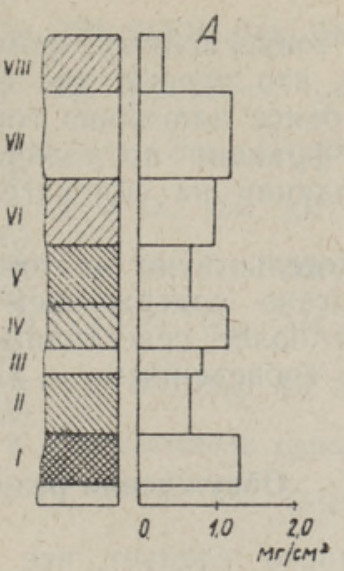

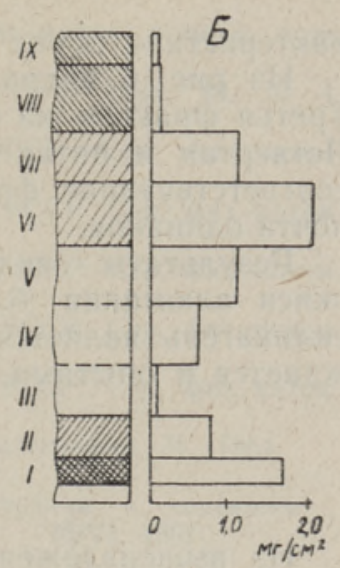

E

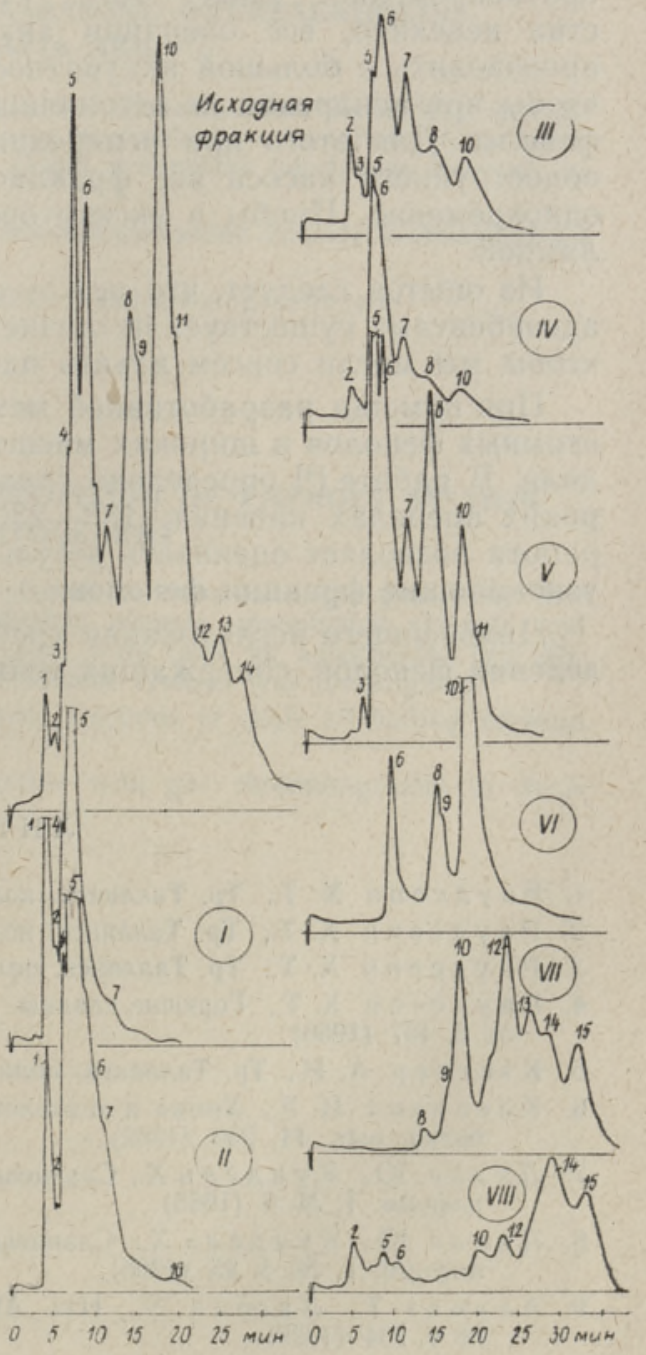


рактеристика обеих тонкослойных хроматограмм приведена на рис. 6 .

Из рис. 6 видно, что первые две фракции по составу одинаковы. Третья фракция на окиси алюминия гораздо шире, чем на силикагеле. Четвертая и пятая фракции по количеству компонентов богаче, чем соответствующие фракции на силикагеле. Состав последних фракций почти одинаков.

Результаты свидетельствуют о том, что отдельные фракции на окиси алюминия богаче содержанием компонентов. Следовательно, силикагель является более селективным адсорбентом. Это подтверждается и опытами, проведенными с индивидуальными фенолами.

\section{Обсуждение результатов}

Из вышензложенного следует, что выработанная нами методика дает возможность легко определять групповой состав фенолов. Эту методику можно использовать для выяснения группового состава узкокипящих и ширококипящих фракций. Провеление анализа просто и кратковременно. Ввиду того, что количество разделяемого вещества невелико, все операции анализа следует во избежание потерь производить с большой аккуратностью. Особенно надо следить за тем, чтобы при испарении не отгонялись вместе с растворителем частично и фенолы. Для этого при испарении остатков растворителя в вакууме водоструйного насоса все фракционные пробы ставились в эксикатор одновременно. Пробы в эксикаторе слегка подогревали инфракрасной лампой.

Из опытов следует, что между окисью алюминия и силикагелем как адсорбентами существует различие. Однако это различие не так велико, чтобы мы могли совсем изъять один из них.

При помощи разработанной методики определяли содержание двухатомных фенолов в широких масштабах. Ранее такой работы не проводили. В работе [4] определено содержание двухатомных фенолов в широких пределах кипения: $180-230,230-265$ и $265-315^{\circ}$. Настоящая работа позволяет оценивать результаты точнее, так как анализировали узкокипящие фракции фенолов.

Дальнейшего исследования требует еще не решенная проблема разделения фенолов, содержащих нейтральный кислород.

\section{ЛИТЕРАТ У РА}

1. Р а удсепп Х. Т., Тр. Таллинск. политехн. ин-та. Сер. А, № 63, 90 (1955).

2. Р а удсе пп Х. Т., Тр. Таллинск. политехн. ин-та. Сер. А, № 73, 120 (1956)

3. Р а удсепп Х. Т., Тр. Таллинск. лолитехн. ин-та. Сер. А, № 73, 133 (1956).

4. Р а удсепп Х. Т., Горючне сланцы. Химия и технология. Ин-т химии АН ЭССР, № 2, 107 (1956).

5. К эстнер А. И., Тр. Таллинск. политехн. ин-та. Сер. А, № 198, 15 (1962).

6. Клесмент И. Р., Химня и технология горючих сланцев и продуктов их переработки, вып. 11, 259 (1962).

7. Лилле Ю., Кундель Х., Сланцевая и химическая промышленность. Сер. техн. информ. 1, № 6 (1965).

8. Лилле Ю., Кундель Х., Сланцевая н химическая промышленность. Сер. техн. информ. 1, № 4, 25 (1966).

9. Алумяэ Т., Л агеда Э., Изв. АН ЭССР. Сер. физ.-матем. и техн. наук, 8, № 4, 234 (1959). 
10. Клесмент И., Л агеда Э., Изв. АН ЭССР. Сер. физ.матем. и техн. наук, 13, № 4, 290 (1964).

11. Клесмент И., Изв. АН ЭССР. Сер. физ.матем. и техн. наук, 13, № 4. 305 (1964).

12. Клесмент И., Л агед А., Эйзеғ О., Изв. АН ЭССР. Сер. физ.-матем. и техн. наук, 14, № 2, 266 (1965).

13. Салусте С., Клесмент И., Эйзен О., Изв. АН ЭССР. Сер. физ.матем. и техн. наук, 14, № 1,141 (1965).

14. Салусте С., Клесмент И., Эйзен О., Изв. АН ЭССР. Сер. физ.-матем. и техн. наук, 14, № 4, 596 (1965).

15. Клесмент И., Касберг А., Эйзен О., Изв. АН ЭССР. Сер. физ.-матем. и техн. наук, 15, № 1, 98 (1966).

16. Эйзен О., Халлик А., Клесмент И., Изв. АН ЭССР. Сер. физ.-матем. и техн. наук, 15, № 2, 230 (1966).

17. Ахрем А. А., К узнец в а А. К., Тонкослойная хроматография, М., 1964.

\section{Ннститут химии}

Академии наук Эстонской ССР
Поступила в редакцию 16/VI 1967

1. VAHESSAAR, I. KLESMENT, O. EISEN

\section{FENOOLIDE GRUPIKOOSSEISU MÄARAMINE OHUKESEKIHILISE KROMATOGRAAFIA ABIL}

Uuriti fenoolifraktsioonide lahutamise vōimalust ōhukeses kihis üksikuteks gruppideks, nimelt kahe- ja ühealuselisteks fenoolideks ia neutraalseteks ühenditeks. Adsorbentidena kasutati alumiiniumoksiidi ja silikageeli. Jälgiti gruppideks lahutamise teravust eri lahustite puhul.

Määrati kahealuseliste fenoolide sisaldus tunnelahjufenoolide kitsaste keemispiiridega $\left(290-350^{\circ} \mathrm{C}\right)$ fraktsioonides.

Ohukeses kihis lahutamise tulemusi kontrolliti gaasikromatograafia abil.

\section{VAHESSAAR, I. KLESMENT, O. EISEN}

\section{DETERMINATION OF THE GROUP COMPOSITION OF PHENOLS BY THIN LAYER CHROMATOGRAPHY}

The possibility was studied of separating phenol fractions to single groups by thin layer chromatography. These groups were dihydric phenols, monohydric phenols and neutral compounds. Aluminium oxide and silicagel were used as adsorbents. The efficiency of separation to single groups in various solvent systems was investigated.

The content of dihydric phenols in the phenol fractions of shale oil boiling between $290-350^{\circ} \mathrm{C}$ was determined.

Thin layer chromatography was used together with gas chromatography to check up the results obtained. 